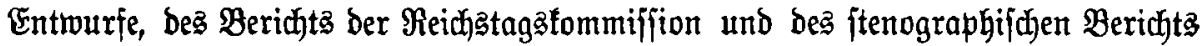
über bie Berhandlungen bes Reidjataga angegeben.

$\mathfrak{D} a \mathfrak{s}$ Werf zerfält in fechs Teile, von benen bie erjten fünf ben fünf $\mathfrak{B u ̈ c h j e r n ~}$

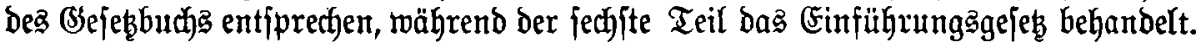

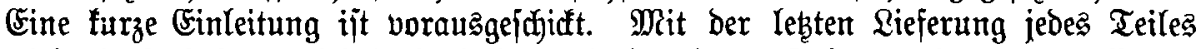

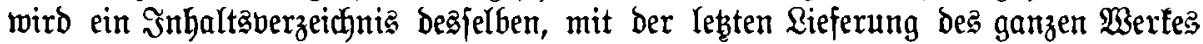
ein alphabetifhes Sadjregifter ausgegeben werden.

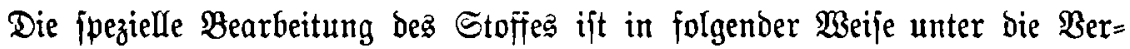

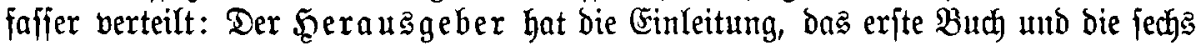

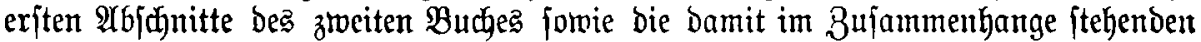

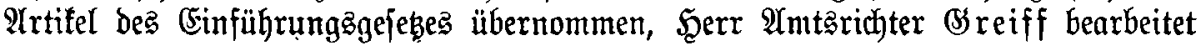

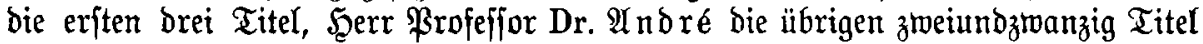

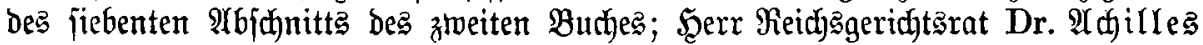

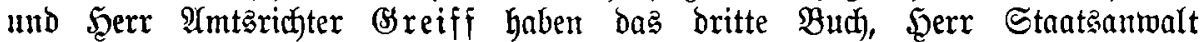

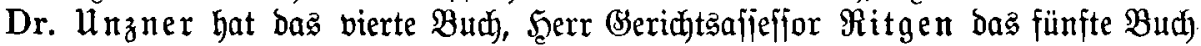
übernommen. Jeber Dex Serren twird zugleid) bie feinen Teil betreffenden $\mathfrak{U}$ rtifel

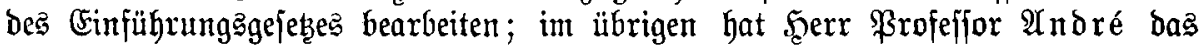
(Finführumgảgefę übernommen.

Infolge biejer Teilung ber Arbeit wiro eine Beriffiedentheit bes Stileả und ber $\mathfrak{A}$ rt ber Darjtellung nicht ganz zu vermeiben jein. Die jachliche Eintheitlichfeit bes ganzen $\mathfrak{B e r f e z}$ mirb aher burty bie unter ben Berfaffern getroffene Berein= barung und bie bem Şerausgeber ofliegende Reitung bes Unternehmens gefiffert.

(Söttingen, im Februar 1897.

\title{
Der sorausgefer.
}

\section{Bormort zur dritten Auflage.}

Die in bem Borworte z̆ur erjten $\mathfrak{A}$ flage hervorgehobenen allgemeinen Gefitht:

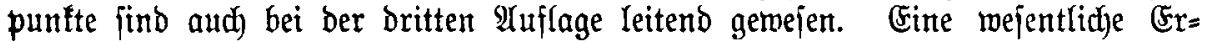
weiterung hat bas $\mathfrak{W e r f}$ in ber britten $\mathfrak{A}$ uflage burch bie tunlichjt volltänoige

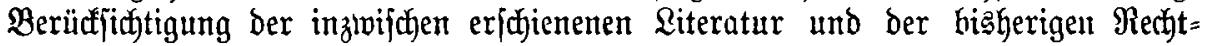
iprechung erfahren. Bei Der Erörterung ber einzelnen Fragen find indefjen, um Raum zu erfparen, nicht immer alle Schriftiteller, bie fïh über bie betreffenden

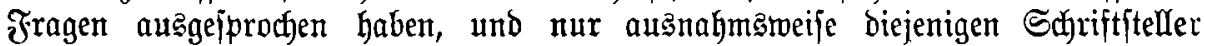
citiert, welche mit ber in bem Fiommentare bertretenen 2 (nfifit übereinftimmen. Differtationen find regelmäß̈g nidft citiert. In Dem Duellenberzeichniffe find bie 
Eeiten ber $\mathfrak{B r o t o f}$ flle Der zmeiten Rommiffion nidft mehr nach ben metallographierten, ionoern lesiglich nach ben georuften Frototollen citiert.

Bon ben Berfaffern ber bisherigen $\mathfrak{H}$ uflagen ift Şerr Reidfggeridhtşrat

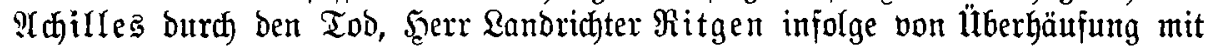

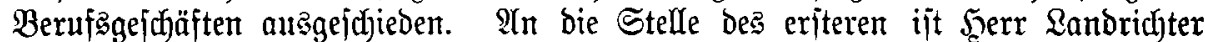
Strecfer, an bie Stelle des leseteren Seerr Frofejpor Strohal getreter. Die in

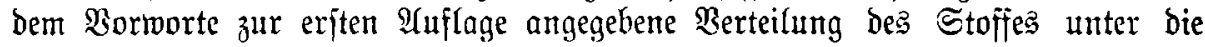
Berfafier, meldye jdjon in ben biahgerigen $\mathfrak{A} u f l a g e n$ bie in ben Borworten zum ¿ritten, fünften und fechjiten Bande angegebenen S̈lnderungen erfahren hatte, ift für bie britte $\mathfrak{A}$ uflage in folgender Meije erfolgt:

Den eriten Band hat ber Seraugaeber bearbeitet. Bon bem g weiten

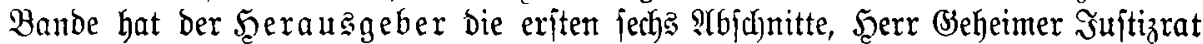

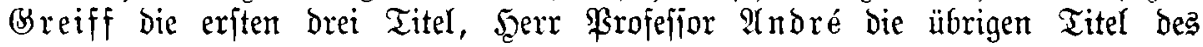
jiebenten 9 (bidjnitts äbernommen. Sn bem britten Bante wirb bie Einteitung,

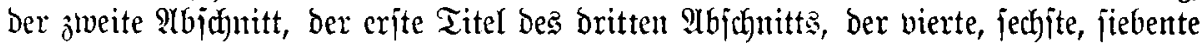

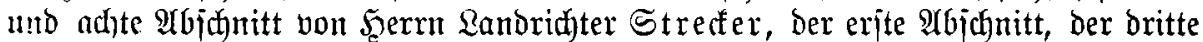

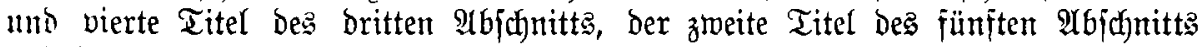

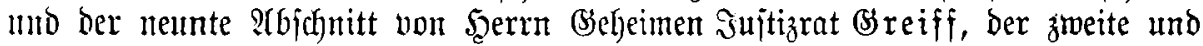
fünfte Titel bes britten 1 (bjonnitts, fowie ber erjte und britte Titel bes fünften :̧ffanitts non bem Serausgeber bearbeitet. Die Bearbeitung bes vierten Bantes ift von Serrn Sberregierungarat $\mathfrak{u}_{\mathfrak{n}}$ zner, bie Bentbeitung bes fünften Bannes ijt von Seern Frofelfor Strohal übernonmen. Bon bem jechjten Bande uerben bie fich jpeziell anj bas Eachenredft und bas Familienrecht be=

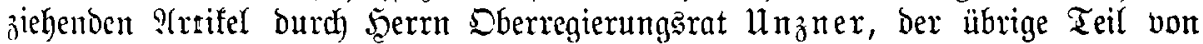

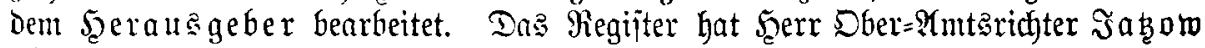
überitommerr.

(B) öttingen, im Alugujt 1903.

\section{Der Sorausgeber.}

